\title{
Occupational asthma due to hexahydrophthalic anhydride: a case report
}

\author{
C B E Chee, H S Lee, T H Cheong, Y T Wang, S C Poh
}

Hexahydrophthalic anhydride (HHPA) belongs to the family of acid anhydrides, the members of which are reactive organic chemicals of low molecular weight widely used in alkyd and epoxy resins. The major toxic effects of the acid anhydrides are mucosal and skin irritation and respiratory hypersensitivity, particularly asthma. Most of the reported cases of asthma caused by acid anhydrides were due to phthalic anhydride. Cases of asthma caused by tetrachlorophthalic anhydride, himic anhydride, maleic anhydride, and pyromellitic dianhydride have also been reported. ${ }^{1}$ Although HHPA has been implicated as a cause of asthma in a study by Moller $e t$ $a l$, this was based on clinical histories obtained from four out of 27 workers exposed to HHPA and the finding of specific IgE to HHPA in $44 \%$ of these exposed workers. ${ }^{2}$ In none of these cases was the diagnosis confirmed by specific challenge testing.

We report a case of asthma induced by occupational exposure to HHPA who showed a bronchoconstrictive response to specific inhalation challenge with HHPA. To our knowledge, this is the first such reported case.

\section{Case report}

The patient is a 43 year old Chinese man, a lifelong non-smoker, with a history of childhood asthma and atopy. He had been free of asthmatic attacks for more than 20 years until his present illness. He started work as a laboratory technician in February 1989 in a factory manufacturing coating chemicals. Several months after starting the job, he began to experience cough, wheezing, and chest tightness that required inhaled and oral salbutamol for relief. His symptoms usually occurred about four to five minutes after exposure to the chemical fumes and would last up to seven hours unless relieved by medicine. He also experienced nocturnal attacks of breathlessness during the course of the working week. His symptoms

Department of Medicine III, Tan Tock Seng Hospital, Moulmein Road, Singapore 1130, Republic of Singapore

C B E Chee, T H Cheong, Y T Wang, S C Poh

Department of Industrial Health, Ministry of Labour, Singapore

H S Lee improved when he was away from work, on weekends, and during vacations.

\section{Occupational exposure}

The factory produces a two component epoxy based chemical designed for the encapsulation of optoelectronic displays and components. The product is a liquid and comes in Part A (epoxy resin) and Part B (curing agent containing up to $70 \%$ HHPA). The HHPA ( $98 \%$ pure), a solid at room temperature, is heated to $70^{\circ} \mathrm{C}$ to liquefy it (in sealed drums). The liquid HHPA is then pumped into a tank where it is blended with other additives (for example, an amine). The blended mixture (now called Part B) is put into plastic bottles and sealed under nitrogen. Our patient's job was to supervise the two workers who carried out this blending process. His job as a laboratory technician also involved taking samples of part B for quality checks in the laboratory. The part B was heated up to $130^{\circ} \mathrm{C}$ in a fume cupboard in the laboratory for 10 to 15 minutes. Our patient noted that he tended to develop symptoms whenever these two processes with HHPA were carried out (several times a month). He suspected that HHPA could be the cause of his symptoms. No environmental measurements were taken. The other workers carrying out blending or working in the laboratory did not appear to be symptomatic.

\section{SERIAL MEASUREMENTS OF PEAK FLOW AT HOME AND} WORK

Peak expiratory flow rates (PEFR) were measured every three hours from waking to sleeping over one month. The mean peak flow rate improved during the week at home and deteriorated during the working week (fig 1).

\section{SPECIFIC BRONCHIAL PROVOCATION TESTING}

Bronchial provocation testing was on an inpatient basis. On the first day, provocation was carried out with the patient standing over a small empty tin (at table height) that was heated by an electric stove for 15 minutes up to a maximum of $90^{\circ} \mathrm{C}$. His PEFR was monitored regularly during the course of the day (fig 2). No asthmatic attack was experienced and the diurnal variation was $11 \%$. 


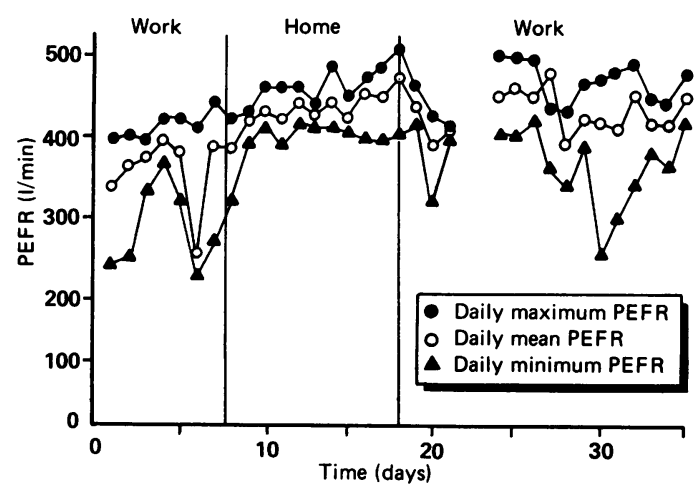

Figure 1 Peak expiratory flow monitoring at work and at home.

On the second day, provocation testing was carried out with the patient standing over the same tin, which this time contained about $200 \mathrm{ml}$ of pure HHPA. The tin was heated for 10 minutes up to a maximum of $92^{\circ} \mathrm{C}$. After five minutes of exposure, the patient experienced cough, lacrimation, and chest tightness, with rhonchi heard in the lungs. His PEFR dropped from a baseline of $470 \mathrm{l} / \mathrm{min}$ to $315 \mathrm{l} / \mathrm{min}$ (a fall of $33 \%$ ) and continued to fall to $278 \mathrm{l} / \mathrm{min}$ (a fall of $41 \%$ ) at ten minutes, when exposure to HHPA was stopped. After a further five minutes, his symptoms worsened with his PEFR falling to $215 \mathrm{l} / \mathrm{min}$ (a fall of $54 \%$ ). He required two doses of ventolin nebulisation for relief of his breathlessness.

He remained relatively comfortable until six hours later when he again experienced breathlessness with rhonchi heard in the lungs, with his PEFR falling to $145 \mathrm{l} / \mathrm{min}$ (a fall of $69 \%$ from a baseline of $470 \mathrm{l} / \mathrm{min}$ ). Nebulised ventolin was administered and relieved his symptoms. Sixteen hours later he was awakened in the middle of the night with a severe asthmatic attack. He was unable to record his PEFR. The attack was again relieved by nebulised ventolin (fig 2 ).

Two of us, who were standing next to him throughout the ten minutes of exposure to heated HHPA, did not develop any respiratory symptoms.

Several days after the challenge testing, he was again admitted with poor control of his asthmatic symptoms and required systemic corticosteroids for control of his asthma.

\section{OTHER INVESTIGATIONS}

The patient's total white cell count was $13.9 \times 10^{9} / 1$, of which $3 \%$ were eosinophils. His chest $x$ ray film was normal. Skin prick tests to common environmental allergens were positive to house dust and house dust mite.

\section{Discussion}

Our patient experienced an immediate and delayed reaction as well as a nocturnal attack of asthma in response to challenge testing to HHPA. This dual response is characteristic of most of the reported cases of asthma caused by the acid anhydrides. ${ }^{1}$ That our patient had an increase in bronchial hyperreactivity after the challenge was evidenced by his nocturnal asthmatic attack and his readmission several days later for poorly controlled symptoms. An association of the late asthmatic response with non-specific bronchial hyperresponsiveness has been shown in one previous study with acid anhydrides. ${ }^{3}$

Most cases of acid anhydride induced asthma appeared to develop in the first few years of exposure. This was also the case in our patient who developed symptoms several months after exposure to HHPA.

Our patient was atopic. Whether this predisposed him to develop asthma to the HHPA is uncertain. So far no study of asthma caused by acid anhydrides has noted any strong association with atopy.

Allergic contact dermatitis to HHPA has been reported based on positive patch tests to HHPA. ${ }^{4}$ This first report of a documented asthmatic response to HHPA based on a specific challenge test together with the demonstration of HHPA specific IgE by other studies ${ }^{25}$ provides good evidence for the inclusion of HHPA as a cause of occupational asthma.

We thank Dr S L Gan for referring this patient for investigation of occupational asthma.

1 Venables KM. Low molecular weight chemicals, hypersensitivity, and direct toxicity: the acid anhydrides. $\mathrm{Br} J$ Ind Med 1989;46:222-32.

2 Moller DR, Gallagher JS, Bernstein DI, Wilcox TG, Burroughs IL. Detection of IgE-mediated respiratory sensitization in

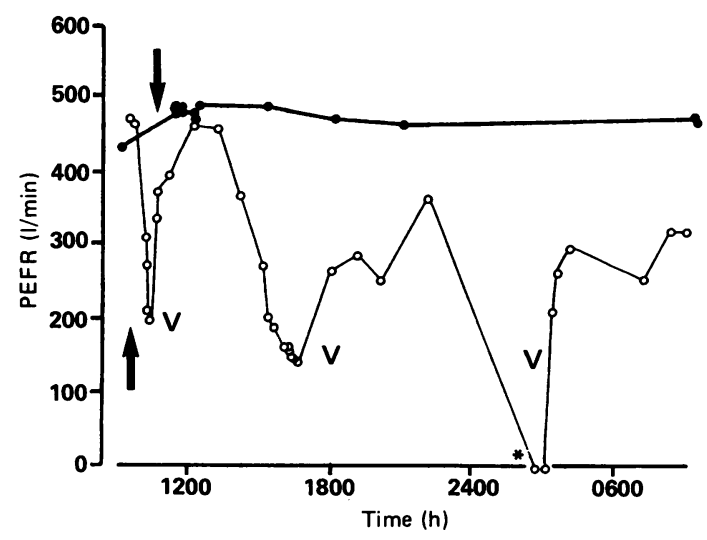

Figure 2 Peak expiratory flow on control day and after exposure to HHPA: PEFR on control day; $\bigcirc$ PEFR after exposure to HHPA; $\downarrow$ time of exposure to control; $\uparrow$ time of exposure to $H H P A ; \vee$ nebulised ventolin administered; $\star$ patient unable to record PEFR. 
workers exposed to hexahydrophthalic anhydride. J Allergy Clin Immunol 1985;75:663-72.

3 Durham SR, Graneck BJ, Hawkins R, Newman Taylor AJ. The temporal relationship between increases in airway responsiveness to histamine and late asthmatic responses induced by occupational agents. J Allergy Clin Immunol 1987;79:398-406.

4 English JSC, Foulds I, White IR, Rycroft RJG. Allergic contact sensitization to the glycidyl ester of hexahydrophthalic acid in a cutting oil. Contact dermatitis 1986;15:66-85.

5 Bernstein DI, Gallagher JS, D'Souza L, Bernstein IL.

Heterogeneity of specific IgE responses in workers sensitized to acid anhydride compounds. J Allergy Clin Immunol 1984; 74:794-801.

Accepted 14 January 1991 